\title{
The Effect of Methylphenidate on the Hearing of Children with Attention Deficit Hyperactivity Disorder
}

\author{
Onur İsmi $^{1} \quad$ Veli Yildirim ${ }^{2} \quad$ Yusuf Vayisoglu $^{1} \quad$ Anis Togrul $^{1} \quad$ Fevziye Toros $^{2} \quad$ Murat Unal $^{1}$ \\ ${ }^{1}$ Department of Otorhinolaryngology, Mersin Üniversitesi, \\ Mersin, Turkey \\ 2 Department of Child and Adolescent Psychiatry Mersin Üniversitesi, \\ Mersin, Turkey \\ Address for correspondence Onur İsmi, Assistant Professor, \\ Department of Otorhinolaryngology, Mersin University, Mersin \\ üniversitesi hastanesi çiftlikköy kampüsü Kulak Burun Boğaz a.d, \\ Mersin 33190, Turkey (e-mail: dronurismi@gmail.com).
}

Int Arch Otorhinolaryngol 2018;22:220-224.

\begin{abstract}
Introduction There has been a sudden idiopathic hearing loss case presented after methylphenidate treatment in a child with attention deficit hyperactivity disorder (ADHD).

Objective This study was performed to reveal the probable ototoxic side effects of methylphenidate use in patients with ADHD.

Methods Thirty pediatric patients with ADHD were included in the study. Pure tone audiometry, speech discrimination scores, waves I, III, V absolute latencies and waves IIII, I-V, III-V interpeak latencies at the $80 \mathrm{~dB} \mathrm{nHL}$ intensity after click stimulus auditory brainstem response (ABR) results were compared before and 3 months after methylphenidate treatment.

Keywords

- methylphenidate

- attention deficit hyperactivity disorder

- hearing

Results There were no statistically significant difference between pretreatment and posttreatment pure tone and speech audiometry findings and $A B R$ results $(p>0.05$ for all parameters).

Conclusion Methylphenidate can be regarded as a safe drug regarding ototoxic side effects. Additional studies with a larger sample size and longer follow-up may be needed.
\end{abstract}

\section{Introduction}

Attention deficit hyperactivity disorder (ADHD) is a common neurobehavioral developmental disease characterized by symptoms of inattention and/or hyperactivity inconsistent with developmental level affecting $\sim 3-5 \%$ of school aged children. ${ }^{1}$ It is the most frequent pediatric neurodevelopmental disorder with a prevalence of $3-12 \%{ }^{2}$ It is not only a disease but a social problem, since patients have significant functional disabilities such as lower school success, academic underachievement, difficulties in interpersonal relationships and low self-esteem. It affects the patients' capacity for cognition, perception and attention. Early man- agement is important because untreated patients have a tendency to substance abuse and antisocial behavior later in life. ${ }^{1}$ Exact underlying pathogenesis is not known, a primary deficit in the inhibitory control due to dysfunction in the prefrontal cortex was supposed to be the main cause of hyperactivity or impulsive behavior. Imaging studies showed that there are subtle anomalies in caudate and corpus callosum size and shape with reduction in the right frontal area. In the metabolic studies with positron emission tomography (PET) imaging, abnormalities of cerebral metabolism in the prefrontal and premotor areas of frontal cortex have been detected. As a result, abnormalities in the frontal network (frontostriatal dysfunction) were supposed to be the received

January 17, 2017

accepted

June 28, 2017

published online

August 7, 2017
DOI https://doi.org/

10.1055/s-0037-1605367.

ISSN 1809-9777.
Copyright $\odot 2018$ by Thieme Revinter

Publicações Ltda, Rio de Janeiro, Brazil
License terms

()(1) $\Theta \circledast$ 
main underlying cause. ${ }^{3}$ A cerebellar insult was also proposed, since children with ADHD could hardly perform tasks requiring time discrimination and estimation, which are mainly controlled by cerebellum. ${ }^{4}$

The main first-line treatment protocol for ADHD is the central nervous system (CNS) stimulant pharmacotherapy, including methylphenidate (MTP) and amphetamine. Methylphenidate is the most common prescribed medication in cases of ADHD. The exact mechanism of its beneficial effect for ADHD is not known, but it blocks presynaptic dopamine and norepinephrine reuptake, while also inhibiting monoamine oxidase. ${ }^{4}$ It is effective as a first-line treatment protocol in $75-80 \%$ of ADHD cases. $^{5}$ The Cochrane database system review of $2015^{6}$ pointed out that MTP may improve teacher-reported ADHD symptoms, teacherreported general behavior and parent-reported quality of life among children and adolescents diagnosed with ADHD. It seems to be a paradox for using a psychostimulant in the treatment of hyperactive patients, but actually, it is the child's control systems that are being stimulated. ${ }^{7}$

Methylphenidate is generally a safe drug, with common adverse effects being nausea, stomach pain, decreased appetite, insomnia, and headache. Transient motor tics, chronic tics, dysphoria, mood lability and hallucinations are seen less commonly. Cardiovascular effects with sudden unexplained death may also be seen very rarely. ${ }^{4}$ Adverse effects on growth and weight gain are controversial. ${ }^{5}$

Recently, Karapinar et $a l^{8}$ presented a pediatric patient having sudden idiopathic hearing loss 24 hour after usage of MTP for ADHD. Hearing loss in children may mimic symptoms of ADHD, such as inattention, and it can complicate the treatment options when seen together with ADHD. ${ }^{9}$ Since the effect of MTP on the auditory pathway is not known, in this first study, we aimed to show the effects of MTP on hearing and auditory pathways by analyzing the pure tone audiometry, speech discrimination, and auditory brainstem response (ABR) results.

\section{Materials and Methods}

Local ethical committee approval was acquired for the present study. Thirty patients diagnosed with ADHD according to the diagnostic and statistical manual of mental disorders $(\mathrm{DSM}-5)^{10}$ criteria were taken to the current study. There were $17(56.6 \%)$ boys and 13 (43.4\%) girls. The mean age was 11.06 (ranging from 6 to 15). All of the patients were treated with the osmotic release oral system MTP medication, brand name Concerta (Janssen Pharmaceuticals Inc., Beerse, Belgium). Otoscopic examinations to all of them were performed by the same physician before the treatment and on the third month control visits. Tympanometry was performed on all patients before audiologic testing. Only the ones with normal otoscopic findings and normal tympanometry (Type A) were taken to the current study. The patients with hearing loss, ototoxic medication use, and previous ear surgery history were excluded. Pure tone audiometry and speech discrimination scores, tested using the AC40 clinical audiometer (Interacoustics, Middelfart, Denmark), as well as click stimulus ABRs, using BERA 4000 (Homoth Medizinelektronik GmbH\&Co, Hamburg, Germany) were performed on all patients before and 3 months after the treatment. Pure tone averages were calculated using means of four tone $(0.5$, $1,2,4 \mathrm{kHz}$ ) frequencies. In the ABR results, waves I, III, V absolute latencies and waves I-III, I-V, III-V interpeak latencies at the $80 \mathrm{~dB}$ nHL intensity were assessed. The pretreatment results of each parameter were compared with the posttreatment results statistically.

\section{Statistical Analysis}

All continuous measurements in the pre- and posttreatment pure tone audiometry and speech discrimination results were tested for normality using the Shapiro-Wilk test. The significance value was set at $p<0.05$. As measurements did not display a normal distribution, non-parametric method Wilcoxon signed-rank test was used for independent groups' comparison.

Statistical analysis was performed using the Statistical Package for Social Sciences, version 11.5 (SPSS, Inc, Chicago, IL). The significance value was set at $p<0.05$.

\section{Results}

All the values of air and bone conduction threshold levels were within their normal limits $(\leq 15 \mathrm{~dB}),{ }^{11}$ both in the preand posttreatment results. There was no statistically significant difference between the average pure tone air conduction and the bone conduction threshold levels after treatment in either the right or left ears $(p=0.305$ for right ears and $p=0.883$ for left ears in the air conduction levels, $p=0.726$ for right ears and $p=0.589$ for left ears in the bone conduction threshold levels). There was no statistically significant difference for speech discrimination scores for right and left ears when pre- and post-treatment values were compared ( $p=0.475$ for right ears and $p=0.829$ for left ears). Comparison of pure tone audiometry and speech discrimination scores was summarized in - Table 1.

When ABR results were compared, the Wilcoxon signedrank test showed no statistically significant difference between pre- and post-treatment values of right ears' wave I absolute latencies. $(p=0.226)$. The paired samples $t$-test also showed that there were no statistically significant differences between the pre- and post-treatment results of other ABR parameters (-Table 2).

\section{Discussion}

In this study, we found that MTP therapy for children with ADHD had no statistically significant effect on pure tone audiometry, speech audiometry and ABR findings.

Hearing and speech development is important for behavioral stability. Children with hearing loss were reported to have significantly more conduct and hyperactivity problems compared with their normal hearing controls. ${ }^{12}$ Beside its direct effect, the adverse effect of hearing loss on the language skills can cause communication and behavioral 
Table 1 Comparison of pretreatment and posttreatment results of pure tone audiometry and speech discrimination scores for right and left ears

\begin{tabular}{|l|l|l|l|}
\hline Parameter & Mean & SD & P \\
\hline Pretreatment right ears' average air conduction threshold & 11.86 & 3.72 & 0.305 \\
\hline Posttreatment right ears' average air conduction threshold & 10.66 & 3.67 \\
\hline Pretreatment right ears' average bone conduction threshold & 3.66 & 3.45 & 0.726 \\
\hline Posttreatment right ears' average bone conduction threshold & 3.43 & 2.58 & 0.475 \\
\hline Pretreatment right ears' speech discrimination scores & 98.5 & 2.67 & 4.03 \\
\hline Posttreatment right ears' speech discrimination scores & 98 & 2.56 & 0.883 \\
\hline Pretreatment left ears' average air conduction threshold & 10.23 & 3.99 & 3.39 \\
\hline Posttreatment left ears' average air conduction threshold & 10.16 & 2.52 & 0.589 \\
\hline Pretreatment left ears' average bone conduction threshold & 3.83 & 2.91 & 0.829 \\
\hline Posttreatment left ears' average bone conduction threshold & 3.43 & 99 & 1.4 \\
\hline Pretreatment left ears' speech discrimination scores & 99.4 & \\
\hline Posttreatment left ears' speech discrimination scores & & \\
\hline
\end{tabular}

Abbreviations: SD, standard deviation.

problems. $^{12}$ A slightly higher incidence of ADHD is seen among deaf patients ranging from $3.5-38.7 \%$, especially the ones with acquired hearing loss are at greater risk. ${ }^{7,13}$ Parasnis et $\mathrm{al}^{13}$ postulated that decrement in the auditory perception in the CNS can cause reorganization of the visual attention from central to peripheral so that individuals can be alert to their surroundings. This decreases the central visual attention scores and impulsive response behavior also

Table 2 Comparison of pretreatment and posttreatment results of auditory brainstem responses with paired samples t-test

\begin{tabular}{|c|c|c|c|c|c|c|c|}
\hline \multicolumn{8}{|c|}{ Paired samples $t$ test } \\
\hline & & \multicolumn{5}{|c|}{ Paired differences } & \multirow{3}{*}{$\begin{array}{l}\text { Sig. } \\
\text { (2-tailed) }\end{array}$} \\
\hline & \multirow[b]{2}{*}{ Parameter (millisecond) } & \multirow[b]{2}{*}{ Mean } & \multirow[b]{2}{*}{ SD } & \multirow[b]{2}{*}{ SE Mean } & \multicolumn{2}{|c|}{$\begin{array}{l}95 \% \mathrm{Cl} \text { of the } \\
\text { difference }\end{array}$} & \\
\hline & & & & & Lower & Upper & \\
\hline Pair 1 & $\begin{array}{l}\text { Pretreatment-Posttreatment LE } \\
\text { wave I absolute latency }\end{array}$ & 0.02000 & 0.11371 & 0.02076 & -0.02246 & 0.06246 & 0.343 \\
\hline Pair 2 & $\begin{array}{l}\text { Pretreatment-Posttreatment LE } \\
\text { wave III absolute latency }\end{array}$ & 0.00667 & 0.11171 & 0.02039 & -0.03504 & 0.04838 & 0.746 \\
\hline Pair 3 & $\begin{array}{l}\text { Pretreatment-Posttreatment LE } \\
\text { wave V absolute latency }\end{array}$ & 0.03300 & 0.15322 & 0.02797 & -0.02421 & 0.09021 & 0.248 \\
\hline Pair 4 & $\begin{array}{l}\text { Pretreatment-Posttreatment LE } \\
\text { wave I-III interpeak latency }\end{array}$ & -0.01267 & 0.15200 & 0.02775 & -0.06942 & 0.04409 & 0.651 \\
\hline Pair 5 & $\begin{array}{l}\text { Pretreatment-Posttreatment LE } \\
\text { wave I-V interpeak latency }\end{array}$ & 0.01100 & 0.19021 & 0.03473 & -0.06003 & 0.08203 & 0.754 \\
\hline Pair 6 & $\begin{array}{l}\text { Pretreatment-Posttreatment LE } \\
\text { wave III-V interpeak latency }\end{array}$ & 0.02433 & 0.14626 & 0.02670 & v0.03028 & 0.07895 & 0.370 \\
\hline Pair 7 & $\begin{array}{l}\text { Pretreatment-Posttreatment RE } \\
\text { wave III absolute latency }\end{array}$ & -0.04933 & 0.17261 & 0.03151 & -0.11379 & 0.01512 & 0.128 \\
\hline Pair 8 & $\begin{array}{l}\text { Pretreatment-Posttreatment RE } \\
\text { wave } \mathrm{V} \text { absolute latency }\end{array}$ & -0.04867 & 0.19894 & 0.03632 & -0.12295 & 0.02562 & 0.191 \\
\hline Pair 9 & $\begin{array}{l}\text { Pretreatment-Posttreatment RE } \\
\text { wave I-III interpeak latency }\end{array}$ & -0.00667 & 0.18087 & 0.03302 & -0.07420 & 0.06087 & 0.841 \\
\hline Pair 10 & $\begin{array}{l}\text { Pretreatment-Posttreatment RE } \\
\text { wave I-V interpeak latency }\end{array}$ & -0.00767 & 0.23312 & 0.04256 & -0.09471 & 0.07938 & 0.858 \\
\hline Pair 11 & $\begin{array}{l}\text { Pretreatment-Posttreatment RE } \\
\text { wave III-V interpeak latency }\end{array}$ & -0.00033 & 0.14736 & 0.02690 & -0.05536 & 0.05469 & 0.990 \\
\hline
\end{tabular}

Abbreviations: $\mathrm{Cl}$, confidence interval; LE, left ear; RE, right ear; SD, standard deviation; SE, standard error. 
increase in these individuals. Children with inattention can show functional hearing loss properties without an actual pathology. ${ }^{14}$ Moreover, hearing loss accompanying ADHD can complicate the treatment with exaggerating symptoms and need multidisciplinary approach. ${ }^{7,9}$ In this manner, if there is an adverse effect of MTP on hearing during the treatment of ADHD, this must be well known.

Methylphenidate is a 1:1 mixture of two isomers, dextrothreo-methylphenidate and levo-threo-methylphenidate. When taken orally, it goes under enteric and hepatic reesterification process to ritalinic acid. The D-isomer of MTP is the pharmacologically active part. ${ }^{15}$ It is a sympathomimetic drug that has similar morphology with endogenous catecholamines. Methylphenidate is thought to act in the CNS by enhancing noradrenergic and dopaminergic neurotransmission and blocking presynaptic reuptake of these transmitters; it also inhibits monoamine oxidase. ${ }^{3,4}$ At the end, it increases the extracellular dopamine and noradrenaline concentration in the prefrontal cortex, striatum and nucleus accumbens. With up-regulated dopamine transporter activity, it also attenuates the striatal neural activity. ${ }^{16}$ Central acting property of MTP was shown with functional magnetic resonance imaging studies that single dose application increased the frontostriatal network, mostly the inferior frontal gyrus. ${ }^{17}$ With positron emission tomography (PET) studies, it was demonstrated that MTP primarily increased the norepinephrine concentration in the thalamus and locus cereleus, whereas it enhanced dopamine transmission mostly in the striatum. ${ }^{18,19}$ Methylphenidate also normalizes the impaired auditory information processing in ADHD with normalizing the auditory event related potentials. $^{20}$

Psychostimulants including MTP are among the safest drugs in the treatment of ADHD. Most of the side effects of stimulant treatment are dose dependent, mild to moderate in severity and decrease with reduction of the dose and changing the timing of the medication. They commonly subside in the first 1 to 2 weeks of treatment, whereas the adverse effects are also the leading cause of medication interruption. $^{21}$ The most common side effects of MTP are nausea, stomach pain, decreased appetite, insomnia, and headache. ${ }^{4}$ Less commonly seen are tics, dysphoria, mood lability and hallucinations. ${ }^{4}$ Cardiovascular side effects are seen very rarely, tachycardia and palpitation are seen in up to $5 \%$ of cases. ${ }^{22}$ The ear, nose and throat side effects of MTP include cough, nasal congestion, nasopharyngitis, pharyngitis and rhinitis, which are rarely seen. Dry mouth is seen more commonly, with up to $12-24 \%$ of cases. ${ }^{22}$ Regarding otologic adverse effects, otitis media ${ }^{23}$ and sudden idiopathic hearing $\operatorname{loss}^{8}$ were reported. In the case report presented by Karapinar et $\mathrm{al}^{8}{ }^{8}$ an 8 -year-old girl admitted with sudden sensorineural hearing loss, 24 hours after the initiation of treatment with MTP. The probable underlying causes were excluded with routine blood tests and magnetic resonance imaging studies. Despite full dose steroid treatment and hyperbaric oxygen therapy, significant improvement in the affected ear could not be achieved. In a recent questionnaire study investigating the adverse effects of medications used in
ADHD treatment, ${ }^{24} 2$ out of 200 children (1\%) with MTP monotherapy and 1 out of 200 children $(0.5 \%)$ with MTP + melatonin therapy were postulated to have hearing problems during treatment, according to their parents, but the type and degree of the hearing losses and their relationship with the treatment were not given. Since the main effect of MTP is on the CNS, the effect of treatment on the retrocochlear auditory pathway was also investigated in our study. In the ABR results, a normal wave I latency with delayed wave I-III or wave I-V interpeak latency suggests a retrocochlear pathology; speech discrimination scores are also disproportionately reduced compared with pure tone average threshold values in the audiometry. ${ }^{25}$ We found that all of the results of pure tone and speech audiometries were within the normal limits and there was no statistically significant difference after the therapy with MTP. Retrocochlear pathway investigation with wave I-III, wave I-V interpeak latencies and speech discrimination scores did not present any adverse effects after treatment. Although the hearing loss was attributed to the MTP medication, the case report presented by Karapinar et $\mathrm{al}^{8}$ may be a coincidence of MTP therapy and sudden hearing loss in the same patient. Another possibility is the endolymphatic hydrops causing sensorineural hearing loss, because the patient had aural fullness and the hearing loss had progressively worsened. Finally, an accompanying perilymph fistula as a reason of progressive sensorineural hearing loss could not be excluded.

\section{Conclusion}

In conclusion, this preliminary report may present that MTP can be regarded as a safe drug without adverse effects on pure tone, speech audiometry findings and auditory brainstem response results in patients with ADHD. Additional studies with a larger number of patients and longer followup periods or experimental studies with cochlear electron microscopic findings may be more supportive for investigating its ototoxic side effects.

\section{References}

1 Noorbala AA, Akhondzadeh S. Attention-deficit/hyperactivity disorder: etiology and pharmacotherapy. Arch Iran Med 2006;9 (04):374-380

2 Rodopman-Arman A, Perdahli-Fiş N, Ekinci O, Berkem M. Sleep habits, parasomnias and associated behaviors in school children with attention deficit hyperactivity disorder (ADHD). Turk J Pediatr 2011;53(04):397-403

3 Biederman J, Spencer T, Wilens T. Evidence-based pharmacotherapy for attention-deficit hyperactivity disorder. Int J Neuropsychopharmacol 2004;7(01):77-97

4 Dopheide JA, Pliszka SR. Attention-deficit-hyperactivity disorder: an update. Pharmacotherapy 2009;29(06):656-679

5 Kang KD, Yun SW, Chung U, et al. Effects of methylphenidate on body index and physical fitness in Korean children with attention deficit hyperactivity disorder. Hum Psychopharmacol 2016;31 (02):76-82

6 Storebø OJ, Ramstad E, Krogh HB, et al. Methylphenidate for children and adolescents with attention deficit hyperactivity 
disorder (ADHD). Cochrane Database Syst Rev 2015;(11): CD009885

7 Kelly D, Forney J, Parker-Fisher S, Jones M. Evaluating and managing attention deficit disorder in children who are deaf or hard of hearing. Am Ann Deaf 1993;138(04):349-357

8 Karapinar U, Saglam O, Dursun E, Cetin B, Salman N, Sahan M. Sudden hearing loss associated with methylphenidate therapy. Eur Arch Otorhinolaryngol 2014;271(01):199-201

9 Lance EI, Shapiro BK. Confounding diagnoses in the neurodevelopmental disabilities population: a child with hearing loss, absence epilepsy, and attention-deficit hyperactivity disorder (ADHD). J Child Neurol 2013;28(05):645-647

10 American Psychiatric Association. Diagnostic and statistical manual of mental disorders (5th ed.). Washington. DC; 2013

11 Katz J, Medwetsky L, Burkard RF, et al. Handbook of clinical audiology. 6th ed. Baltimore: Lippincott Williams \& Wilkins; 2009

12 Stevenson J, McCann D, Watkin P, Worsfold S, Kennedy C; Hearing Outcomes Study Team. The relationship between language development and behaviour problems in children with hearing loss. J Child Psychol Psychiatry 2010;51(01):77-83

13 Parasnis I, Samar VJ, Berent GP. Deaf adults without attention deficit hyperactivity disorder display reduced perceptual sensitivity and elevated impulsivity on the Test of Variables of Attention (T.O.V.A.). J Speech Lang Hear Res 2003;46(05):1166-1183

14 Ashitani M, Ueno C, Doi T, Kinoshita T, Tomoda K. Clinical features of functional hearing loss with inattention problem in Japanese children. Int J Pediatr Otorhinolaryngol 2011;75(11):1431-1435

15 May DE, Kratochvil CJ. Attention-deficit hyperactivity disorder: recent advances in paediatric pharmacotherapy. Drugs 2010;70 (01):15-40

16 Chou TL, Chia S, Shang CY, Gau SS. Differential therapeutic effects of 12-week treatment of atomoxetine and methylphenidate on drug-naïve children with attention deficit/hyperactivity disorder: A counting Stroop functional MRI study. Eur Neuropsychopharmacol 2015;25(12):2300-2310
17 Rubia K, Halari R, Cubillo A, et al. Methylphenidate normalizes fronto-striatal underactivation during interference inhibition in medication-naïve boys with attention-deficit hyperactivity disorder. Neuropsychopharmacology 2011;36(08):1575-1586

18 Hannestad J, Gallezot JD, Planeta-Wilson B, et al. Clinically relevant doses of methylphenidate significantly occupy norepinephrine transporters in humans in vivo. Biol Psychiatry 2010; 68(09):854-860

19 Volkow ND, Wang GJ, Fowler JS, et al. Evidence that methylphenidate enhances the saliency of a mathematical task by increasing dopamine in the human brain. Am J Psychiatry 2004;161(07): 1173-1180

20 Ozdag MF, Yorbik O, Ulas UH, Hamamcioglu K, Vural O. Effect of methylphenidate on auditory event related potential in boys with attention deficit hyperactivity disorder. Int J Pediatr Otorhinolaryngol 2004;68(10):1267-1272

21 Efron D, Jarman F, Barker M. Side effects of methylphenidate and dexamphetamine in children with attention deficit hyperactivity disorder: a double-blind, crossover trial. Pediatrics 1997;100(04): 662-666

22 Aagaard L, Hansen EH. The occurrence of adverse drug reactions reported for attention deficit hyperactivity disorder (ADHD) medications in the pediatric population: a qualitative review of empirical studies. Neuropsychiatr Dis Treat 2011;7:729-744

23 Greenhill LL, Muniz R, Ball RR, Levine A, Pestreich L, Jiang H. Efficacy and safety of dexmethylphenidate extended-release capsules in children with attention-deficit/hyperactivity disorder. J Am Acad Child Adolesc Psychiatry 2006;45(07):817-823

24 Tobaiqy M, Stewart D, Helms PJ, et al. Parental reporting of adverse drug reactions associated with attention-deficit hyperactivity disorder (ADHD) medications in children attending specialist paediatric clinics in the UK. Drug Saf 2011;34(03):211-219

25 Kileny PR, Zwolan TA. Diagnostic Audiology. In; Flint PW, Haughey BH, Lund VJ, Niparko JK, Richardson MA, Robbins KT, Thomas JR, eds. Cummings Otolaryngology Head \& Neck Surgery (5th ed). Philadelphia: Mosby Elsevier; 2010 